\title{
Adsorption interaction of carrier-free thallium species with gold and quartz surfaces
}

\author{
By A. Serov ${ }^{1,2, \#}$, R. Eichler ${ }^{1,2, *}$, R. Dressler ${ }^{1}$, D. Piguet ${ }^{1}$, A. Türler ${ }^{1,2}$, A. Vögele ${ }^{1}$, D. Wittwer ${ }^{1,2}$ and H. W. Gäggeler ${ }^{1,2}$ \\ ${ }^{1}$ Laboratory for Radiochemistry and Environmental Chemistry, Paul Scherrer Institute, CH-5232 Villigen, Switzerland \\ 2 Departement for Chemistry and Biochemistry, University Bern, CH-3012 Bern, Switzerland
}

(Received November 27, 2012; accepted in revised form January 11, 2013)

(Published online April 22, 2013)

\section{Thallium / Thallium hydroxide / Adsorption / \\ Thermochromatography / Sublimation}

\begin{abstract}
Summary. The adsorption interactions of thallium and its compounds with gold and quartz surfaces were investigated. Carrier-free amounts of thallium were produced in nuclear fusion reactions of alpha particles with thick gold targets. The method chosen for the studies was gas thermochromatography and varying the redox potential of the carrier gases. It was observed that thallium is extremely sensitive to trace amounts of oxygen and water, and can even be oxidized by the hydroxyl groups located on the quartz surface. The experiments on a quartz surface with $\mathrm{O}_{2}, \mathrm{He}, \mathrm{H}_{2}$ gas in addition with water revealed the formation and deposition of only one thallium species - $\mathrm{TlOH}$. The adsorption enthalpy was determined to be $\Delta H_{\mathrm{ads}}^{\mathrm{SiO}_{2}}(\mathrm{TlOH})=-134 \pm 5 \mathrm{~kJ} \mathrm{~mol}^{-1}$. A series of experiments using gold as stationary surface and different carrier gases resulted in the detection of two thallium species - metallic $\mathrm{Tl}\left(\mathrm{H}_{2}\right.$ as carrier gas $)$ and $\mathrm{TlOH}$ $\left(\mathrm{O}_{2}, \mathrm{O}_{2}+\mathrm{H}_{2} \mathrm{O}\right.$ and $\mathrm{H}_{2}+\mathrm{H}_{2} \mathrm{O}$ as pure carrier gas or carrier gas mixture) with $\Delta H_{\mathrm{ads}}^{\mathrm{Au}}(\mathrm{Tl})=-270 \pm 10 \mathrm{~kJ} \mathrm{~mol}^{-1}$ and $\Delta H_{\text {ads }}^{\mathrm{Au}}(\mathrm{TlOH})=-146 \pm 3 \mathrm{~kJ} \mathrm{~mol}^{-1}$. These data demonstrate a weak interaction of $\mathrm{TlOH}$ with both quartz and gold surfaces. The data represent important information for the design of future experiments with the heavier homologue of $\mathrm{Tl}$ in group 13 of the periodic table - element 113 (E113).
\end{abstract}

\section{Introduction}

During the last twelve years several heavy transactinides $(\mathrm{Bh}, \mathrm{Hs}, \mathrm{Cn}$, and $\mathrm{Fl}$ ) have been characterized chemically [1-7]. Model experiments with their lighter homologues $(\mathrm{Re}, \mathrm{Os}, \mathrm{Hg}$ and $\mathrm{Pb}$ ) at carrier free conditions were mandatory prior to real experiments with superheavy elements (SHE). On one hand they help to design experimental setups as well as the investigation of the most likely chemical reactions. On the other hand a direct comparison with lighter homologues in the corresponding groups of the periodic table at the same experimental conditions helps to

\footnotetext{
*Author for correspondence (E-mail: robert.eichler@psi.ch).

\# Present adress: Department of Chemical and Nuclear Engineering and Center for Emerging Energy Technologies, 209 Farris Engineering Center, University of New Mexico, Albuquerque, NM 87131, USA.
}

understand the chemical processes and allows for a tentative speciation of the transactinide compounds formed. So far, elements heavier than seaborgium have been investigated by gas phase chemical means only. Gas phase chemical investigations provide certain advantages, such as 1) fast transport for the studied elements; 2) formation of the most stable chemical species; 3 ) simple preparation of ideal samples for alpha spectroscopy and spontaneous fission (SF) fragment spectroscopy. Recently, experiments on the investigation of the chemical properties from element 113 (E113) based on isothermal gas chromatography are under way at the Flerov Laboratory for Nuclear Reactions, in Dubna, Russia. Therefore, information on the gas phase chemical behavior of the lighter homologues of E113, indium and thallium, is crucial. A detailed study of adsorption properties of different indium species on quartz and gold surfaces was published in a previous work [8]. It was found that single atomic indium is very sensitive to oxygen and water traces and forms a volatile species - InOH. Additionally it was claimed that metallic indium is less volatile compared to its hydroxide. Thallium represents the nearest homologue of E113. An attempt to investigate the volatility of elemental thallium was made already in the 1970-ies [9]. It was found that carrierfree thallium deposited on quartz surfaces at $T_{\text {dep }}=330 \pm$ $20^{\circ} \mathrm{C}$, and this deposition was attributed to metallic $\mathrm{Tl}$. In the present work we report new adsorption chromatography data for two thallium species which we ascribed to metallic $\mathrm{Tl}$ and $\mathrm{TlOH}$. The microscopic model of gas adsorption chromatography, implemented into a Monte-Carlo simulation code [10], was used to derive the standard adsorption enthalpy at zero surface coverage $\left(\Delta H_{\mathrm{ads}}\right)$ of ${ }^{200} \mathrm{Tl}$ species on quartz and gold surfaces from the experimental results.

\section{Experimental}

\section{$2.1^{200} \mathrm{Tl}$ production}

Long-lived ${ }^{200} \mathrm{Tl}\left(T_{1 / 2}=26.1 \mathrm{~h}\right)$ was produced in nuclear fusion reactions via irradiation of a ${ }^{\text {nat }} \mathrm{Au}$ target with ${ }^{4} \mathrm{He}$ at the PSI PHILIPS cyclotron applying beam intensities between $10^{11}-10^{12}$ particles per second. A stack of metallic gold targets, with $30 \mu \mathrm{m}$ thickness each, was irradiated with ${ }^{4} \mathrm{He}$ entering the target with an energy of $39 \pm 3 \mathrm{MeV}$. The pro- 
duction cross sections of thallium isotopes in the nuclear fusion reactions of ${ }^{4} \mathrm{He}$ and ${ }^{\text {nat }} \mathrm{Au}$ were estimated to be in the $0.1-1$ barn region (see Fig. 1) from TENDL-2009 calculations [11]. The obtained gold targets were cut into pieces which were used directly as sources for offline thermochromatography experiments.

\subsection{Thermochromatographic experiments with ${ }^{200} \mathrm{Tl}$}

The experimental set-up used for the thermochromatography is schematically shown in Fig. 2. The chromatographic column was located inside a hermetically sealed Inconel ${ }^{\circledR}$ tube. The carrier gas inlet and outlet were connected by Swagelok $^{\circledR}$ components. Such a system is effective to maintain high carrier gas purities during an experiment by the exclusion of oxygen and water from the mobile phase. Additionally, a Ta-foil acting as a getter for remaining traces of water and oxygen was placed at the entrance of the chromatographic column and was heated to $950{ }^{\circ} \mathrm{C}$ prior to and during the experiment. A second Ta-getter, kept at $980{ }^{\circ} \mathrm{C}$ was located downstream adjacent to the sample within the temperature gradient (not shown on Fig. 2). This was to ensure the elemental state of thallium evaporating from the source. The gold foil containing ${ }^{200} \mathrm{Tl}$ was positioned inside the start oven at the beginning of the experiment. After the temperature gradient was established and the getter ovens were at $950{ }^{\circ} \mathrm{C}$ the start oven was heated up rapidly within about $5 \mathrm{~min}$ to $1000{ }^{\circ} \mathrm{C}$. Various carrier gases and carrier gas mixtures were used to investigate the chemical properties of different thallium species in several experiments (see Table 1). In case of oxidizing carrier gases both Ta getters were removed. The gas mixtures with included water vapor were produced by passing the gas through a water reservoir held at room temperature.

At the end of the experiment the column was removed from the temperature gradient oven through the cold end. A screening of the activity distribution along the column was performed by a dose meter to roughly identify the position of the activity in the column. Subsequently these positions were measured by gamma spectroscopic measure-

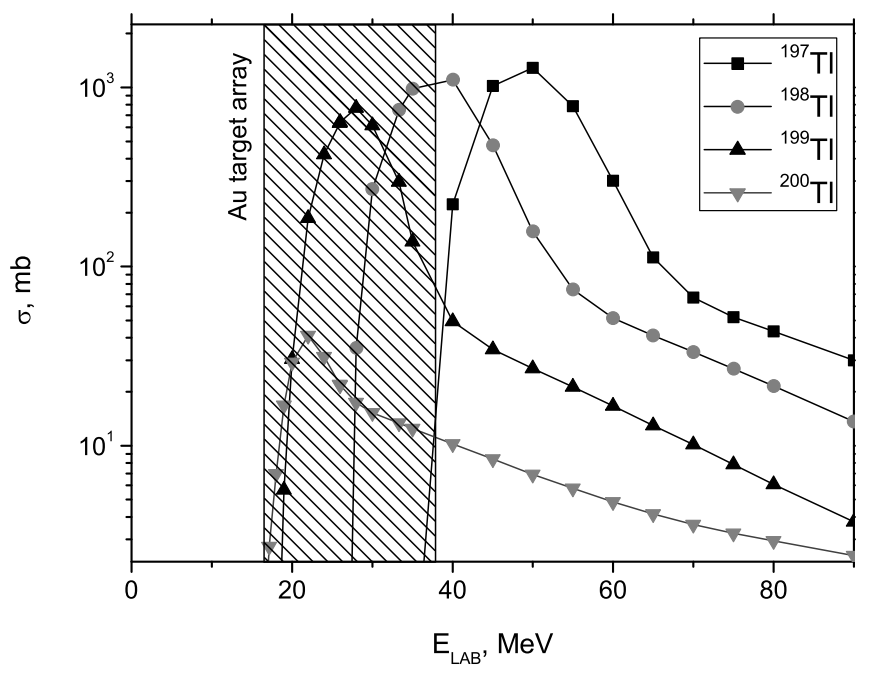

Fig. 1. Production cross-section of different $\mathrm{Tl}$ isotopes in the reaction ${ }^{197} \mathrm{Au}\left({ }^{4} \mathrm{He}, x n\right)$, calculated with the TENDL-2009 code [11]. The energy range of ${ }^{4} \mathrm{He}$ in a target material is indicated.

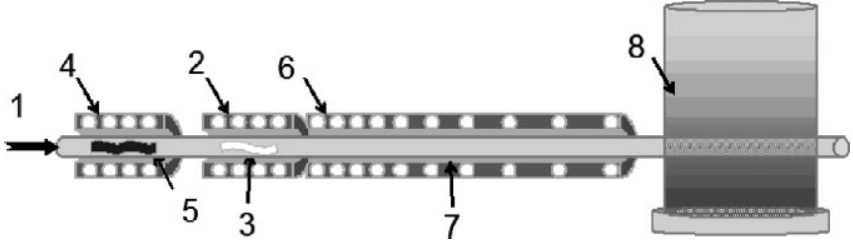

Fig. 2. Thermochromatography set-up. 1 - Carrier gas $\left(\mathrm{He}, \mathrm{H}_{2}, \mathrm{O}_{2}\right.$ or mixtures with water), $2-$ starting oven $\left(1000{ }^{\circ} \mathrm{C}\right), 3-{ }^{200} \mathrm{Tl}$ source on gold foil surface, $4-$ getter oven $\left(950^{\circ} \mathrm{C}\right), 5$ - Ta chips, 6 - gradient oven, 7 - chromatographic column (quartz/gold), inner diameter $4 \mathrm{~mm}$, 8 - cooling system (down to liquid nitrogen temperature, $-186^{\circ} \mathrm{C}$ ).

Table 1. Experimental conditions of thermochromatographic experiments.

\begin{tabular}{llcll}
\hline $\begin{array}{l}\text { Carrier } \\
\text { gas }\end{array}$ & $\begin{array}{l}\text { Statio- } \\
\text { nary } \\
\text { phase }\end{array}$ & $\begin{array}{c}\text { Flow } \\
\text { rate, } \\
\mathrm{min}^{-1}\end{array}$ & $\begin{array}{c}\text { Experiment } \\
\text { duration, } \\
\text { min }\end{array}$ & Expected species \\
\hline $\mathrm{H}_{2}$ & Gold & 15 & $60 / 120$ & $\mathrm{Tl}$ \\
$\mathrm{H}_{2} / \mathrm{H}_{2} \mathrm{O}$ & Gold & 15 & $60 / 120$ & $\mathrm{TlOH}$ \\
$\mathrm{O}_{2}$ & Gold & 25 & $60 / 120$ & $\mathrm{TlO}, \mathrm{TlOH}, \mathrm{Tl}(\mathrm{OH})_{3}$ \\
$\mathrm{O}_{2} / \mathrm{H}_{2} \mathrm{O}$ & Gold & 25 & $60 / 120$ & $\mathrm{TlO}, \mathrm{TlOH}, \mathrm{Tl}(\mathrm{OH})_{3}$ \\
\hline $\mathrm{H}_{2}$ & Quartz & 15 & $60 / 120$ & $\mathrm{Tl}$ \\
\hline $\mathrm{He}$ & Quartz & 25 & $60 / 120$ & $\mathrm{Tl}, \mathrm{TlOH}$ \\
$\mathrm{O}_{2}$ & Quartz & 25 & $60 / 120$ & $\mathrm{TlO}, \mathrm{TlOH}, \mathrm{Tl}(\mathrm{OH})_{3}$ \\
$\mathrm{H}_{2} / \mathrm{H}_{2} \mathrm{O}$ & Quartz & 15 & $60 / 120$ & $\mathrm{TlOH}$ \\
$\mathrm{He} / \mathrm{H}_{2} \mathrm{O}$ & Quartz & 25 & $60 / 120$ & $\mathrm{TlOH}$ \\
$\mathrm{O}_{2} / \mathrm{H}_{2} \mathrm{O}$ & Quartz & 25 & $60 / 120$ & $\mathrm{TlO}, \mathrm{TlOH}, \mathrm{Tl}(\mathrm{OH})_{3}$ \\
\hline
\end{tabular}

ments using a lead collimator (window size $1 \times 1 \mathrm{~cm}$, lead thickness $0.7 \mathrm{~cm}$ ) directly in front of a standard high purity $\mathrm{Ge}$ (HPGe) $\gamma$-detector with $2.13 \mathrm{keV}$ resolution at $1.33 \mathrm{MeV}$ in conjunction with an acquisition and analysis system based on Canberra's Genie $2 \mathrm{k}^{\circledR}$. All other experimental parameters such as gas flow, stationary phase material, and experiment duration are compiled in Table 1. For the experiments with gold as the stationary phase the gradient part of the quartz column was entirely covered inside with rolled gold foils.

\section{Results and discussion}

\subsection{Thermochromatographic experiments with ${ }^{200} \mathrm{Tl}$ on gold as stationary phase}

The deposition temperature determined for thallium on a gold surface using purified hydrogen as carrier gas was $T_{\text {dep }}^{\mathrm{Au}}(\mathrm{Tl})=944 \pm 50^{\circ} \mathrm{C}$ (Fig. 3a). Taking into account the extremely dry and oxygen free conditions as well as the reduction potential of pure hydrogen this deposition was assigned to thallium in its elemental form. The enthalpy of adsorption of elemental thallium on a gold surface was deduced as $\Delta H_{\mathrm{ads}}^{\mathrm{Au}}(\mathrm{Tl})=-279 \pm 6 \mathrm{~kJ} \mathrm{~mol}^{-1}$. in fair agreement with scalar relativistic calculations $[12,13]$ yielding a maximum $\mathrm{Au}_{16}-\mathrm{Tl}$ binding energy of $256 \mathrm{~kJ} / \mathrm{mol}$ and $\operatorname{CCSD}(\mathrm{T})$ caclculations [14] yielding a dissociation energy for the $\mathrm{Tl}-\mathrm{Au}$ molecule of $257 \mathrm{~kJ} / \mathrm{mol}$ and with earlier Eichler-Miedema adsorption model calculations [15, 16], where $-215 \mathrm{~kJ} / \mathrm{mol}$ were estimated for the Au-Tl adsorption interaction. Series of experiments with pure oxygen resulted in the deposition of thallium species at a signifi- 


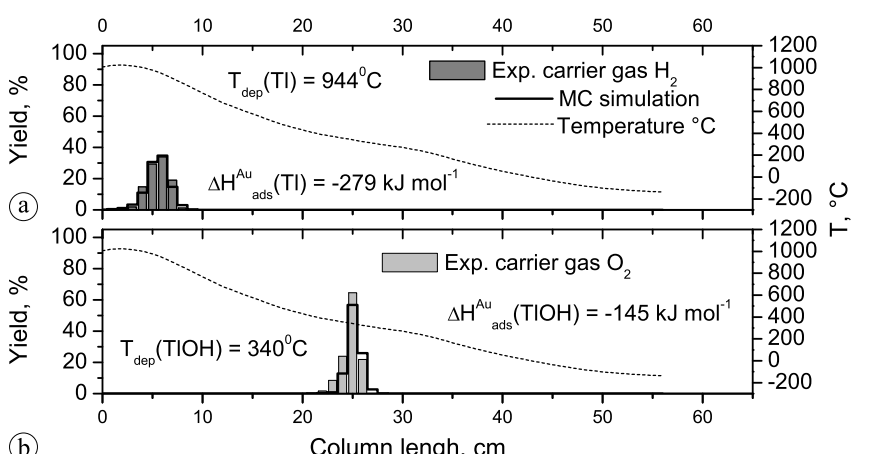

(b)

Column lengh, $\mathrm{cm}$

Fig. 3. Thermochromatograms of ${ }^{200} \mathrm{Tl}$ (dark grey bars, left hand axis, panel A) and ${ }^{200} \mathrm{TlOH}$ (light grey bars, left hand axis, panel B) on gold surface using as carrier gas: (a) $15 \mathrm{ml} \mathrm{min}^{-1} \mathrm{H}_{2}$; (b) $25 \mathrm{ml} \mathrm{min}^{-1} \mathrm{O}_{2}$. The solid stepped lines represent the results of the Monte Carlo simulations applying the adsorption enthalpies given in the panels. The temperature gradients are indicated (dashed line, right hand axis).

cantly lower temperature $T_{\text {dep }}^{\mathrm{Au}}\left(\mathrm{TlO}_{x} \mathrm{H}_{y}\right)=340 \pm 25^{\circ} \mathrm{C}$ related to an adsorption enthalpy $\Delta H_{\text {ads }}^{\mathrm{Au}}\left(\mathrm{TlO}_{x} \mathrm{H}_{y}\right)=-145 \pm$ $3 \mathrm{~kJ} \mathrm{~mol}^{-1}$ (Fig. 3b). Possible species that could be produced at such experimental conditions are: TlO (thermodynamically unstable), $\mathrm{TlOH}, \mathrm{TlOOH}$ and $\mathrm{Tl}(\mathrm{OH})_{3}$. It is well known that the formation of $\mathrm{Tl}^{3+}$ requires a high oxidizing potential; for instance, in the solution it is possible to oxidize $\mathrm{Tl}^{+}$into $\mathrm{Tl}^{3+}$ by using strongly oxidizing reactants, e.g. bromine. On the other hand, in group 13 the stabilization of the oxidation state +1 is observed from $\mathrm{Al}$ to $\mathrm{Tl}$, nonetheless due to relativistic effects [12-14]. Additional experiments were preformed to assign the observed deposition peak to a certain thallium species. A mixture of hydrogen with water was supposed to have a lower oxidation potential and should lead to the formation of $\mathrm{TlOH}$. A $\mathrm{O}_{2} / \mathrm{H}_{2} \mathrm{O}$ mixture should most probably produce $\mathrm{Tl}(\mathrm{OH})_{3}$ or $\mathrm{TlOOH}$ in case the oxidizing potential of the gas mixture is high enough. The results of these experiments are shown in Fig. 4. It can be clearly seen that the reduction potential of hydrogen at high temperatures led to the formation of thallium in its elemental state (Fig. 4a). The deposition temperature as well as the adsorption enthalpy are in reasonable agreement with those obtained during

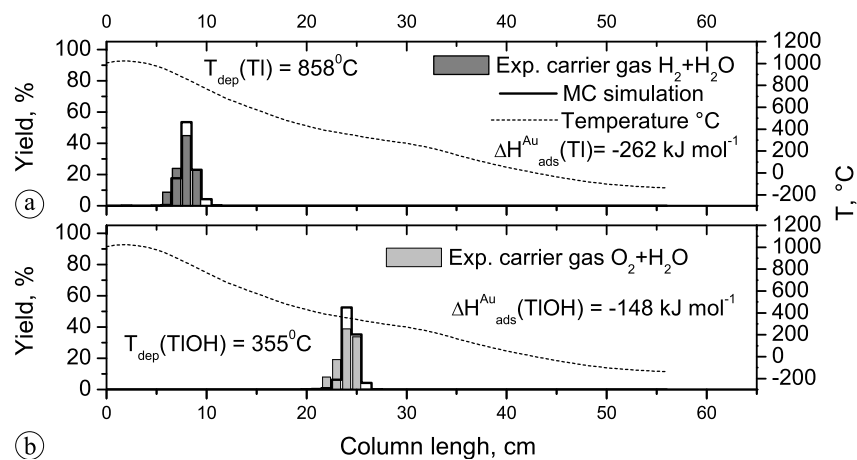

Fig. 4. Thermochromatograms of ${ }^{200} \mathrm{Tl}$ (dark grey bars, left hand axis, a) and ${ }^{200} \mathrm{TlOH}$ (light grey bars, left hand axis, b) on gold surface using as carrier gas: (a) $15 \mathrm{ml} \mathrm{min}^{-1} \mathrm{H}_{2} / \mathrm{H}_{2} \mathrm{O}$ mixture; (b) $25 \mathrm{ml} \mathrm{min}$ min $^{-1}$ $\mathrm{O}_{2} / \mathrm{H}_{2} \mathrm{O}$ mixture. The solid stepped lines represent the results of the Monte Carlo simulations applying the adsorption enthalpies given on the panels. The temperature gradients are indicated (dashed line, right hand axis). the experiments with pure hydrogen: $T_{\mathrm{dep}}^{\mathrm{Au}}(\mathrm{Tl})=858 \pm 50^{\circ} \mathrm{C}$ and $\Delta H_{\mathrm{ads}}^{\mathrm{Au}}(\mathrm{Tl})=-262 \pm 6 \mathrm{~kJ} \mathrm{~mol}^{-1}$. A similar picture was obtained in the case of the $\mathrm{O}_{2} / \mathrm{H}_{2} \mathrm{O}$ mixture used as carrier gas. A deposition temperature $T_{\text {dep }}^{\mathrm{Au}}\left(\mathrm{TlO}_{x} \mathrm{H}_{y}\right)=355 \pm$ $25^{\circ} \mathrm{C}$ was observed. The deduced adsorption enthalpy of the oxidized thallium species is $\Delta H_{\mathrm{ads}}^{\mathrm{Au}}\left(\mathrm{TlO}_{x} \mathrm{H}_{y}\right)=-148 \pm$ $3 \mathrm{~kJ} \mathrm{~mol}^{-1}$ (Fig. 4b). After the second series of experiments it was still impossible to assign the low temperature peak to either $\mathrm{TlOH}$ or $\mathrm{TlOOH} / \mathrm{Tl}(\mathrm{OH})_{3}$. The final assignment to $\mathrm{TlOH}$ was possible only after completing the experiments with thallium in quartz columns (see Sect. 3.2).

\subsection{Thermochromatographic experiments with ${ }^{200} \mathrm{Tl}$ on quartz as stationary phase}

Using all three gases with different oxidation or reduction potential $\left(\mathrm{H}_{2}, \mathrm{He}\right.$, and $\left.\mathrm{O}_{2}\right)$ only one deposited species was observed at a temperature of $T_{\mathrm{dep}}^{\mathrm{SiO}_{2}}\left(\mathrm{TlO}_{x} \mathrm{H}_{y}\right)=300 \pm$ $35^{\circ} \mathrm{C}$. The adsorption enthalpy was determined to be $\Delta H_{\mathrm{ads}}^{\mathrm{SiO}_{2}}\left(\mathrm{TlO}_{x} \mathrm{H}_{y}\right)=-134 \pm 5 \mathrm{~kJ} \mathrm{~mol}^{-1}$ using the Monte Carlo simulation approach [10] (Fig. 5a-c, respectively). It is obvious that even efficient drying and removal of oxygen from the carrier gases $\mathrm{H}_{2}$ and $\mathrm{He}$ are not sufficient for the preservation of thallium in its elemental state. One possible explanation might be that the quartz surface is covered with hydroxyl groups promoting the oxidation of carrier-free amounts of thallium. The deposition temperature found in all three experiments is in perfect agreement with the data reported earlier [9]. In that work the species deposited at $T_{\mathrm{dep}}^{\mathrm{SiO}_{2}}=330 \pm 25^{\circ} \mathrm{C}$ at similar experimental conditions and was assigned to metallic thallium. However, as it can be seen from our experiments with $\mathrm{O}_{2}$ the deposited species should be assigned to thallium hydroxide $\mathrm{TlOH}$. Furthermore, it appears that pure hydrogen and helium should not produce thallium species with the oxidation state +3 . Hence, the low temperature deposition peak was assigned to $\mathrm{TlOH}$ by combining the data obtained during the experiments with gold and quartz surfaces. Relativistic calculations [14] predict a high thermodynamic

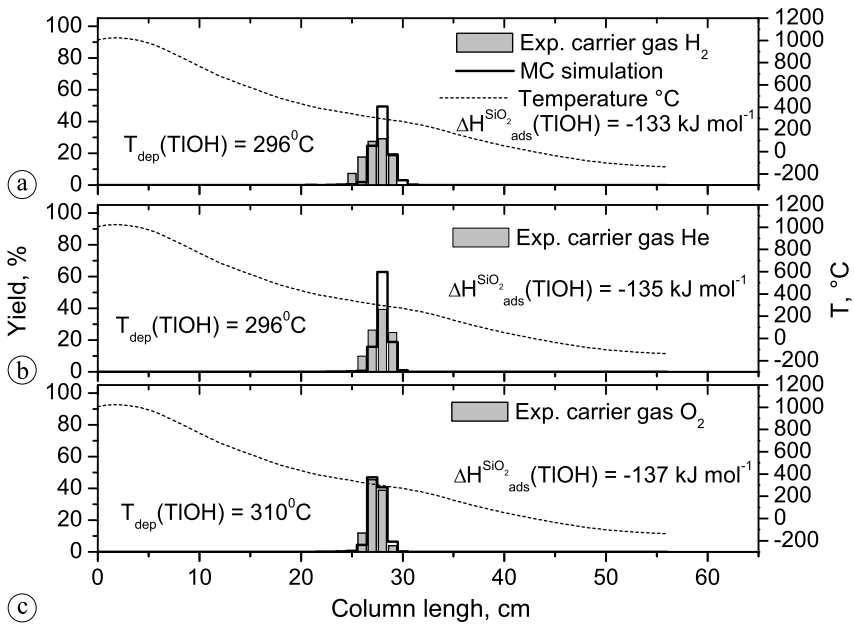

Fig. 5. Thermochromatograms of ${ }^{200} \mathrm{TlOH}$ (light grey bars, left hand axis) on quartz surface using as carrier gas: (a) $15 \mathrm{ml} \mathrm{min}^{-1} \mathrm{H}_{2}$; (b) $25 \mathrm{ml} \mathrm{min}^{-1} \mathrm{He}$; (c) $25 \mathrm{ml} \mathrm{min}^{-1} \mathrm{O}_{2}$. The solid stepped lines represent the results of the Monte Carlo simulations applying the adsorption enthalpies given on the panels. The temperature gradients are indicated (dashed line, right hand axis). 


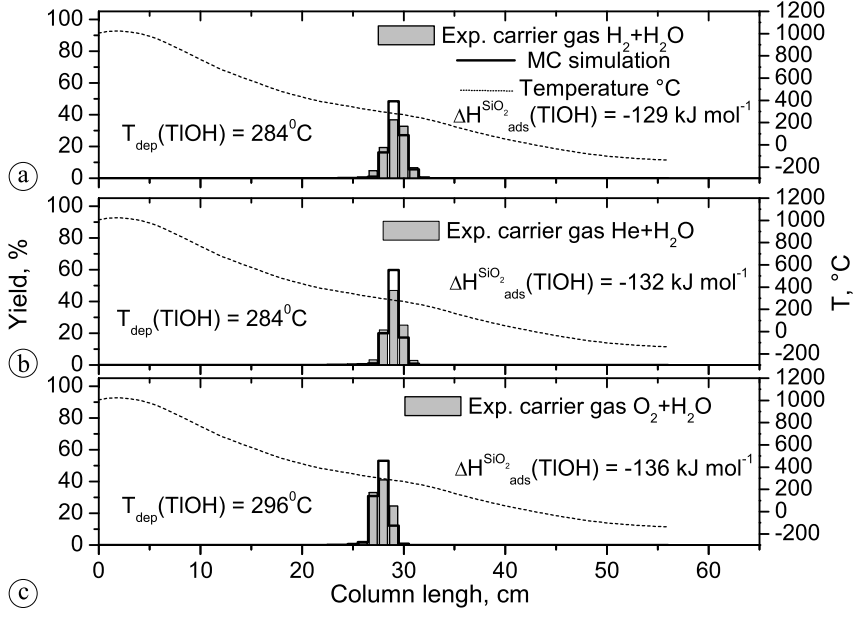

Fig. 6. Thermochromatograms of ${ }^{200} \mathrm{TlOH}$ (light grey bars, left hand axis) on quartz surface using as carrier gas: (a) $15 \mathrm{ml} \mathrm{min}^{-1} \mathrm{H}_{2} / \mathrm{H}_{2} \mathrm{O}$ mixture; (b) $25 \mathrm{ml} \mathrm{min}^{-1} \mathrm{He} / \mathrm{H}_{2} \mathrm{O}$ mixture; (c) $25 \mathrm{ml} \mathrm{min}^{-1} \mathrm{O}_{2} / \mathrm{H}_{2} \mathrm{O}$ mixture. The solid stepped lines represent the results of the Monte Carlo simulations applying the adsorption enthalpies given on the panels. The temperature gradients are indicated (dashed line, right hand axis).

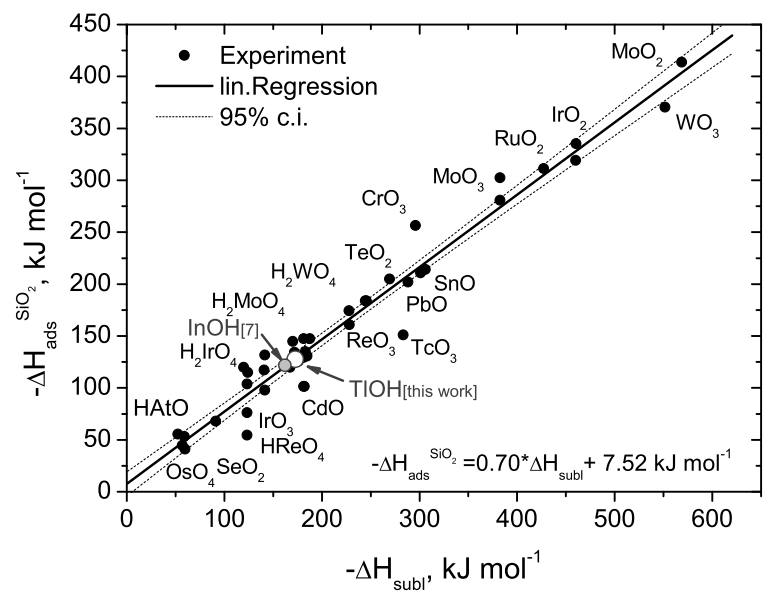

Fig. 7. Correlation of the adsorption enthalpy $\Delta H_{\text {ads }}$ of oxides and hydroxides on inert surfaces with the macroscopic property of sublimation enthalpy $\Delta H_{\text {subl }}$ adapted from [19]. The data for InOH from [17] and $\mathrm{TlOH}$ obtained in this work are highlighted.

stability of $\mathrm{TlOH}$, rendering this assignment to be save. Thus, an adsorption enthalpy was evaluated for $\mathrm{TlOH}$ on quartz to be $\Delta H_{\mathrm{ads}}^{\mathrm{SiO}_{2}}(\mathrm{TlOH})=-132 \pm 4 \mathrm{~kJ} \mathrm{~mol}^{-1}$ (Fig. 6a-c, respectively). The microscopic property adsorption enthalpy obtained for $\mathrm{TlOH}$ on quartz surfaces allow for the estimation of its macroscopic property sublimation enthalpy to be $\Delta H_{\text {subl }}(\mathrm{TlOH})=177 \pm 10 \mathrm{~kJ} \mathrm{~mol}^{-1}$ using the most recent empirical correlation between both properties which is valid for oxidic species on quartz surfaces adopted from [17] (see Fig. 7).

\section{Conclusions}

The adsorption interaction of thallium species with gold and quartz surfaces was studied by the method of gas thermochromatography. It was found that metallic thallium interacts fairly strong with the gold surface as predicted by relativistic calculations [12-14] and also by the EichlerMiedema Model $[15,16]$. Oxidizing carrier gases and their mixture with water produce thallium hydroxide in the oxidation state +1 . The adsorption interaction of $\mathrm{TlOH}$ with gold surfaces is significantly weaker compared to that of metallic thallium. Experiments with quartz as a chromatographic surface revealed a high reactivity of thallium with hydroxyl groups on the $\mathrm{SiO}_{2}$ surface. The deposited species was assigned to thallium monohydroxide in contrast to a previous work [9] that assigned it to metallic thallium. The same deposition peak was found in our experiments with pure $\mathrm{He}$, pure $\mathrm{O}_{2}$ and their mixture with water, leading to the unambiguous identification of $\mathrm{TlOH}$. The sublimation enthalpy of $\mathrm{TlOH}$ was estimated. Thallium is the nearest homologue of E113. Thus, the obtained data can be used in future designs of experimental setups for the chemical investigation of E113. We can conclude that the interaction of members of group 13 with gold is decreasing in the sequence In [17] $>\mathrm{Tl}$. If this trend in the group 13 persists as expected by more recent Miedema calculations [18] and by relativistic calculations [12-14], E113 should be deposited on gold surfaces at lower temperatures than indium and/or thallium.

On the other side, $\mathrm{InOH}$ and $\mathrm{TlOH}$ are much more volatile compared to their metallic state and this property can be used in first experiments with element E113. A slightly higher adsorption interaction with quartz surfaces and a lower volatility of $113 \mathrm{OH}$ compared to $\mathrm{TlOH}$ would be expected following the trend in group 13 of the periodic table. Using an inert gas without drying systems and de-oxidizing agents, or even more - using inert gas-oxygen mixtures as carrier gas shall ensure the chemical state of element 113 as monohydroxide.

Acknowledgment. This work was supported by the Swiss National Science Foundation (grant: 200020-117671/1).

\section{References}

1. Eichler, R., Brüchle, W., Dressler, R., Düllmann, Ch. E., Eichler, B., Gäggeler, H. W., Gregorich, K. E., Hoffman, D. C., Hübener, S., Jost, D. T., Kirbach, U. W., Laue, C. A., Lavanchy, V. M., Nitsche, H., Patin, J. B., Piquet, D., Schädel, M., Shaughnessy, D. A., Strellis, D. A., Taut, S., Tobler, L., Tysganov, Y. S., Türler, A., Vahle, A., Wilk, P. A., Yakushev, A. B.: Chemical characterization of bohrium (element 107). Nature 407, 63 (2000).

2. Düllmann, Ch. E., Dressler, R., Eichler, B., Gäggeler, H. W., Glaus, F., Jost, D. T., Piguet, D., Soverna, S., Türler, A., Brüchle, W., Eichler, R., Jäger, E., Pershina, V., Schädel, M., Schausten, B., Schimpf, E., Schött, H.-J., Wirth, G., Eberhardt, K., Thörle, P., Trautmann, N., Ginter, T. N., Gregorich, K. E., Hoffman, D. C., Kirbach, U. W., Lee, D. M., Nitsche, H., Patin, J. B., Sudowe, R., Zielinski, P. M., Timokhin, S. N., Yakushev, A. B., Vahle, A., Qin, Z.: Chemical investigation of hassium (element 108). Nature 418, 859-862 (2002).

3. Eichler, R., Aksenov, N. V., Belozerov, A. V., Bozhikov, G. A., Chepigin, V. I., Dressler, R., Dmitriev, S. N., Gäggeler, H. G., Gorshkov, V. A., Haenssler, F., Itkis, M. G., Lebedev, V. Y., Laube, A., Malyshev, O. N., Oganessian, Yu. Ts., Petruschkin, O. V., Piguet, D., Rasmussen, P., Shishkin, S. V., Shutov, A. V., Svirikhin, A. I., Tereshatov, E. E., Vostokin, G. K., Wegrzecki, M., Yeremin, A. V.: Chemical properties of ele-ment 112. Nature 447, 72-75 (2007).

4. Eichler, R., Aksenov, N. V., Belozerov, A. V., Bozhikov, G. A., Chepigin, V. I., Dressler, R., Dmitriev, S. N., Gäggeler, H. G., Gorshkov, V. A., Haenssler, F., Itkis, M. G., Lebedev, V. Y., Laube, A., Malyshev, O. N., Oganessian, Yu. Ts., Petruschkin, O. V., 
Piguet, D., Rasmussen, P., Serov, A. A., Shishkin, S. V., Shutov, A. V., Svirikhin, A. I., Tereshatov, E. E., Vostokin, G. K., Wegrzecki, M., Yeremin, A. V.: Thermochemical and physical properties of element 112. Angew. Chem. Int. Ed. 47(17), 3262-3266 (2008).

5. Wittwer, D., Abdullin, F. Sh., Aksenov, N. V., Albin, Yu. V., Bozhikov, G. A., Dmitriev, S. N., Dressler, R., Eichler, R., Gäggeler, H. W., Henderson, R. A., Hübener, S., Kenneally, J. M., Lebedev, V. Ya., Lobanov, Yu. V., Moody, K. J., Oganessian, Yu. Ts., Petrushkin, O. V., Polyakov, A. N., Piguet, D., Rasmussen, P., Sagaidak, R. N., Serov, A., Shirokovsky, I. V., Shaughnessy, D. A., Shishkin, S. V., Sukhov, A. M., Stoyer, M. A., Stoyer, N. J., Tereshatov, E. E., Tsyganov, Yu. S., Utyonkov, V. K., Vostokin, G. K., Wegrzecki, M., Wilk, P. A.: Gas phase chemical studies of superheavy elements using the Dubna gas-filled recoil separator stopping range determination. Nucl. Instrum. Methods B 268(1), 28 (2010).

6. Eichler, R., Aksenov, N. V., Albin, Yu. V., Belozerov, A. V., Bozhikov, G. A., Chepigin, V. I., Dmitriev, S. N., Dressler, R., Gäggeler, H. W., Gorshkov, V. A., Henderson, R. A., Johnsen, A. M., Kenneally, J. M., Lebedev, V. Ya., Malyshev, O. N., Moody, K. J., Oganessian, Yu. Ts., Petrushkin, O. V., Piguet, D., Popeko, A. G., Rasmussen, P., Serov, A., Shaughnessy, D. A., Shishkin, S. V., Shutov, A. V., Stoyer, M. A., Stoyer, N. J., Svirikhin, A. I., Tereshatov, E. E., Vostokin, G. K., Wegrzecki, M., Wilk, P. A., Wittwer, D., Yeremin, A. V.: Indication for a volatile element 114. Radiochim. Acta 38, 133-139 (2010).

7. Eichler, B., Zude, F., Fan, W., Trautmann, N., Herrmann, G.: Volatilization and deposition of ruthenium oxides in a temperature gradient tube. Radiochim. Acta 56, 133 (1992).

8. Serov, A., Eichler, R., Dressler, R., Piguet, D., Türler, A., Vögele, A., Wittwer, D., Gäggeler, H. W.: Gas chromatography of indium in macroscopic and carrier-free amounts using quartz and gold as stationary phases. Radiochim. Acta 99, 95 (2011).
9. Eichler, B.: Investigation of distribution of nuclear reaction products in carrier-free form by thermochromatography method in the hydrogen stream. Dubna report P12-6662 3 (1972).

10. Zvara, I.: Simulation of thermochromatographic processes by the Monte Carlo method. Radiochim. Acta 38, 95 (1985).

11. Koning, A. J., Rochman, D.: TENDL-2009: "Consistent TALYSbased Evaluated Nuclear Data Library including covariance data" JEFF-DOC 1310 (2009), ISBN 92-64-02314-3.

12. Fox-Beyer, B. S., van Wüllen, C.: Theoretical modeling of the adsorption of thallium and element 113 atoms on gold using two-component density functional methods with effective core potentials. Chem. Phys. 395, 95 (2012).

13. Zaitsevskii, A., Titov, A. V. Rusakov, A. A., van Wüllen, C.: $A b$ initio study of element 113 - gold interactions. Chem. Phys. Lett. 508, 329 (2011).

14. Pershina, V., Anton, J., Jacob, T.: Electronic structures and properties of $\mathrm{MAu}$ and $\mathrm{MOH}$, where $\mathrm{M}=\mathrm{Tl}$ and element 113. Chem. Phys. Lett. 480, 157 (2009).

15. Eichler, B.: Bestimmung der Adsorptionswärme gasförmiger Metalle auf festen Metalloberflächen bei Null-Bedeckung. Report ZFK 396, (1979) [in German].

16. Eichler, B., Rossbach, H.: Adsorption of volatile metals on metal surfaces and its application in nuclear chemistry. I. Calculation of adsorption enthalpies for hypothetical super-heavy elements with $Z$ around 114. Radiochim. Acta 33, 121-125 (1983).

17. Serov, A., Aksenov, N., Bozhikov, G., Eichler, R., Dressler, R., Lebedev, V., Petrushkin, O., Piguet, D., Shishkin, S., Tereshatov, E., Türler, A., Vögele, A., Wittwer, D., Gäggeler, H. W.: Adsorption interaction of astatine species with quartz and gold surfaces. Radiochim. Acta 99, 593 (2011).

18. Eichler, B.: Metal chemistry of transactinides. PSI Report 00-09, Villigen (2000), ISSN 1019-0643.

19. Schädel, M. (ed.): The Chemistry of Superheavy Elements. Kluwer Academic Publishers, Dordrecht (2003). 